\title{
Quantification of Economic Impact of Drug Wastage in Oral Oncology Medications: Comparison of 3 Methods Using Palbociclib and Ribociclib in Advanced or Metastatic Breast Cancer
}

\author{
Joseph Biskupiak, PhD, MBA; Gary Oderda, PharmD, MPH; Diana Brixner, PhD, RPh; \\ Derek Tang, PhD, BSPharm; Christopher Zacker, RPh, PhD; and Anand A. Dalal, PhD, MBA
}

\begin{abstract}
BACKGROUND: Discarding unused drugs after dose changes or discontinuation can significantly affect pharmacy budgets. This is especially concerning for expensive oncology agents. However, few economic studies account for drug wastage, providing an inaccurate estimate of a drug's actual economic cost, cost-effectiveness, and value.

OBJECTIVES: To (a) compare the economic impact of drug wastage between ribociclib and palbociclib-clinically similar oral medications for metastatic breast cancer-using 3 approaches (Markov model, pharmacy acquisition cost model, and a retrospective claims analysis) and (b) compare the modeling results with a published estimate of drug wastage for palbociclib from a claims analysis.
\end{abstract}

METHODS: A Markov model and a pharmacy acquisitions cost model were developed to evaluate the economic impact of dose reductions for ribociclib and palbociclib over a 1-year time period. Data inputs were pharmacy costs (RED B00K wholesale acquisition cost) and proportion of patients experiencing dose reductions from either ribociclib randomized clinical trials (MONALEESA-2, -3 , or -7) or real-world observational data (Symphony Health retrospective claims analysis). The latter constituted the third approach for quantifying drug wastage. The economic impact of dose reductions for ribociclib and palbociclib in postmenopausal women with previously untreated HR-positive/HER2-negative advanced breast cancer was assessed. Drug wastage was defined as drug doses that could not be used by a patient following a dose reduction. The cost of drug wastage was defined as the cost associated with an unused drug resulting from a dose reduction. The predicted results from the 2 models were compared with a previously published claims analysis that estimated the effect of treatment costs and drug wastage for palbociclib based on the observed dosing patterns from the Symphony Health Solutions database.

RESULTS: In the Markov model, relative to ribociclib, palbociclib users experienced drug wastage of $\$ 112,382$ total, or $\$ 1,124$ per treated patient, per year due to dose changes. In the pharmacy acquisition cost model, relative to ribociclib, palbociclib usage was associated with an increased cost of $\$ 7,196$ per patient per year (based on a mid-cycle dose reduction) comprising dosing-based cost differences and drug wastage cost for palbociclib of $\$ 3,727$. The previously published claims analysis found that palbociclib users experiencing a dose reduction had drug wastage costs of $\$ 5,471$ per patient.

CONCLUSIONS: In both models, dose reductions for ribociclib patients resulted in no wastage, since unused tablets could be administered in subsequent cycles, while dose reductions for palbociclib resulted in drug wastage and increased costs. The results from both models were consistent with previously published results from the claims analysis, demonstrating drug wastage costs for palbociclib.

J Manag Care Spec Pharm. 2019;25(8):859-66

Copyright $\odot 2019$, Academy of Managed Care Pharmacy. All rights reserved.

\section{What is already known about this subject}

- Discarding unused drugs after dose changes can significantly affect pharmacy costs, especially for expensive oncology agents. Few economic studies account for drug wastage, making estimates of a drug's cost, cost-effectiveness, and value inaccurate.

\section{What this study adds}

Most studies of drug wastage in oncology have focused on intravenous drugs, while this study demonstrates that oral agents are also associated with drug wastage.

Dose reductions for palbociclib may result in drug wastage because higher-strength capsules need to be discarded to step down to a lower dose.

Dose reductions for ribociclib are achieved by altering the number of tablets consumed, potentially reducing drug wastage to zero, since unused tablets can be administered in subsequent cycles.

ૉ $\mathrm{n}$ the era of rising health care costs, drug wastage is an often-overlooked area that could represent an opportunity for health systems and payers to significantly reduce pharmacy expenditures. Drug wastage is the potentially unnecessary disposal of unused or partially used drug ampoules, vials, or syringes, ${ }^{1}$ which can occur in hospital settings, provider clinics, and patient home settings. Historically, drug wastage has only been focused on injectable medications; however, it can also occur with oral dosage forms. Common reasons for drug wastage across a wide variety of diseases include patient improvement, patients forgetting to take their drugs, adverse effects, treatment changes, patient transfers between medical facilities or providers, or dose adjustments..$^{2,3}$

Drug wastage is concerning in all disease states, but in oncology, where the cost of anticancer drugs rose $10 \%$ annually from 1995 to 2013 (about $\$ 8,500$ per patient per year), ${ }^{4}$ payers and providers are beginning to pay particular attention to wastage and how it affects pharmacy budgets. In the United States, anticancer drugs were a $\$ 37$ billion market in 2013, with only 10 patent-protected cancer drugs representing one third of that market. ${ }^{4}$ When a portion of those drugs are discarded after being partially used or discontinued, the cost of that wastage can be significant. 
A 2015 study estimated that up to two thirds of all medications prescribed to U.S. adults were wasted, representing up to $\$ 5.4$ billion per year. $^{2}$ A 2016 report showed that for the top 20 oncology drugs, the proportion of leftover drugs after treatment ranged from $1 \%$ to $33 \%$, and 2 of those drugs alone would be responsible for $\$ 485$ million of discarded drugs. ${ }^{5}$ In 2008, Fasola et al. reported that their Department of Medical Oncology in Italy compared prescription orders with the actual amount of consumed drugs and calculated the net loss from drug wastage as $6.4 \%$ of the department's total budget. ${ }^{1}$

Titration to a patient's drug regimen may not always be achievable with the initial dose in a patient's current prescription, requiring a new prescription and the discarding of the remaining drug from the original prescription. This is especially true for vials or pills that cannot be safely split or saved for later use. ${ }^{6}$ In such instances, patients must obtain new prescriptions from their physicians, usually pay another copay or coinsurance, and in the case of many oncology drugs, wait for the new prescription to be shipped from the specialty pharmacy, which can result in a lapse in treatment.

To illustrate and quantify the problem of drug wastage for oral dosage forms, we used the example of advanced or metastatic breast cancer (mBC), for which a new class of agents called cyclin-dependent kinases 4/6 (CDK-4/6), including ribociclib and palbociclib, are used as first-line oral treatments for women with HR-positive/HER2-negative (HR+/ HER2-) mBC. Palbociclib is available in 3 strengths (125 mg, $100 \mathrm{mg}$, and $75 \mathrm{mg}$ capsules). ${ }^{7}$ Ribociclib, which has similar clinical outcomes to palbociclib, comes in $200 \mathrm{mg}$ tablets, with multiple tablets administered to meet the most commonly prescribed doses (600 mg, $400 \mathrm{mg}$, and $200 \mathrm{mg}$ ). ${ }^{8}$

When a dose reduction occurs with palbociclib, drug wastage may result because of the drug's available dosage strengths and capsule formulation. In contrast, a dose adjustment with ribociclib may be achieved by altering the number of tablets consumed and may reduce related drug wastage to nearly zero, since unused tablets can be used by the individual patient in subsequent cycles, representing significant potential cost savings for patients (drug copayment) and health plans. It is also possible that a patient will receive a new prescription and new blister pack for the new dose, thereby negating any potential cost savings. This analysis focused on the potential savings that could be realized if the number of tablets were adjusted in response to a dose reduction.

The objectives of this study were to estimate and compare the economic impact of dose reductions as quantified by the costs of drug wastage resulting from unused doses of drug using 3 different approaches-2 different modeling approaches, a Markov and pharmacy acquisition cost models, and a retrospective claims analysis. ${ }^{6,9}$

\section{Methods}

Drug dose reduction is a common occurrence after an induction dose with oral CDK-4/6 inhibitors. Drug wastage was defined as drug doses that could not be used by the patient following a dose reduction. A subsequent dose increase after a dose reduction was not observed in any of the clinical trials and was therefore not considered. Using this definition and current dosage forms, it was assumed that dose reductions for palbociclib would result in drug wastage, while dose reductions for ribociclib would only result in unused tablets that could be administered in subsequent cycles.

Ribociclib is supplied as a blister pack of 21 tablets (200 mg per tablet). The $600 \mathrm{mg}$ daily dose comes as 3 blister packs (wholesale acquisition cost [WAC] pricing for a month supply is $\$ 11,955 ; \$ 189.77 /$ tablet), the $400 \mathrm{mg}$ daily dose as 2 blister packs (WAC $\$ 9,564 ; \$ 227.72 /$ tablet), and the $200 \mathrm{mg}$ daily dose as 1 blister pack (WAC \$4,782; \$227.72/tablet). Palbociclib is supplied as a bottle of 21 capsules with capsule strengths of $125 \mathrm{mg}$ (WAC \$11,292; \$537.71/capsule), $100 \mathrm{mg}$ (WAC \$11,292; \$537.71/capsule), and $75 \mathrm{mg}$ (WAC \$11,292; $\$ 537.71$ /capsule). All WAC pricing data was obtained from RED BOOK Online as of June 2018.10

The recommended dose frequency for ribociclib and palbociclib is once daily for 21 consecutive days, followed by 7 days off treatment, for a complete treatment cycle of 28 days. Monitoring after day 14 is recommended for both drugs. For both models, it was assumed that dose reduction would occur after day 14, resulting in 7 days of treatment at a reduced dose.

\section{Markov Model (Approach 1)}

To calculate the per-patient per-year costs of drug wastage due to unused treatment doses, a Markov model (Figure 1) tracked the transition of a hypothetical cohort of advanced breast cancer patients across 3 drug regimens for ribociclib (600 mg, 400 $\mathrm{mg}$, or $200 \mathrm{mg}$ ) or palbociclib (125 mg, $100 \mathrm{mg}$, or $75 \mathrm{mg}$ ). The cohort included 100 ribociclib users and 100 palbociclib users. Transition probabilities were obtained using individual patientlevel data from the MONALEESA-2 (ribociclib) clinical trial and were applied to both treatments. ${ }^{11}$ Since the authors did not have access to similar patient-level data from palbociclib pivotal studies, the same transition probabilities were used for palbociclib. Dose modifications were modeled as occurring in the middle of the treatment cycle, after day 14. The model evaluated the following dose modifications for ribociclib: $600 \mathrm{mg}$ to $400 \mathrm{mg}, 600 \mathrm{mg}$ to $200 \mathrm{mg}$, and $400 \mathrm{mg}$ to $200 \mathrm{mg}$; for palbociclib: $125 \mathrm{mg}$ to $100 \mathrm{mg}, 125 \mathrm{mg}$ to $75 \mathrm{mg}$, and $100 \mathrm{mg}$ to $75 \mathrm{mg}$. The Markov cycle length was 14 days, and the time horizon was 1 year. All patients entered the model at the highest dose and only experienced a one-way transition to a reduced dose. While the model allowed for patients to discontinue a drug, patients that discontinued a drug were not 

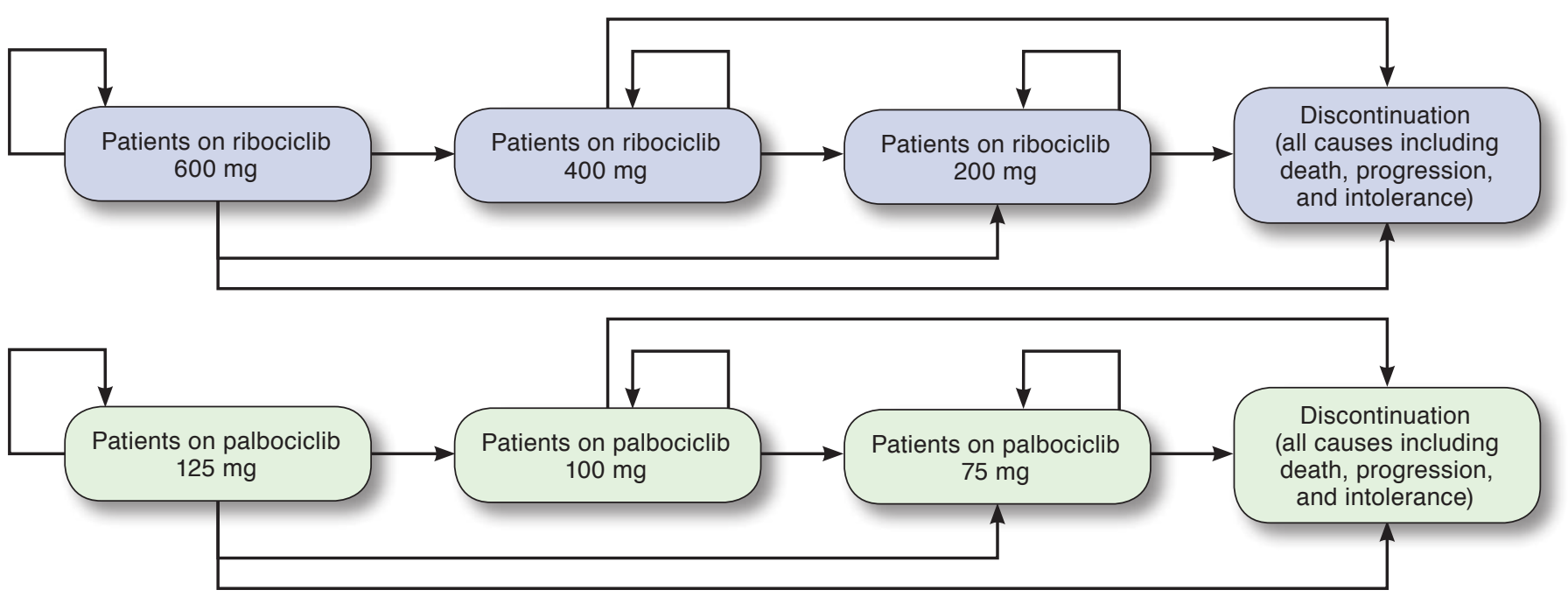

considered in the estimation of drug wastage costs; only drug wastage due to dose reduction was considered.

\section{Pharmacy Acquisition Cost Model (Approach 2)}

The pharmacy acquisition cost (PAC) model estimated the annual drug acquisition costs, which included the cost of drug wastage for ribociclib (base case using dose reduction data from MONALEESA-2 ${ }^{11}$ ) and palbociclib (using dose reduction data from actual clinical practice reported in the Symphony Health Solutions database ${ }^{6}$ ). The PAC model was created with MS Excel (Microsoft, Redmond, WA) and allowed users to modify input vales to account for their actual experience. Users could also use dose reduction data from MONALESSA-3 or MONALESSA-7. Table 1 provides data inputs for the PAC model. Dose modification occurred in the middle of the treatment cycle after day 14. The model evaluated a 1-dose reduction (ribociclib $600 \mathrm{mg}$ to $400 \mathrm{mg}$ or palbociclib $125 \mathrm{mg}$ to $100 \mathrm{mg}$ ) and a 2-dose reduction (ribociclib $600 \mathrm{mg}$ to $400 \mathrm{mg}$ to $200 \mathrm{mg}$ or palbociclib $125 \mathrm{mg}$ to $100 \mathrm{mg}$ to $75 \mathrm{mg}$ ). As in the Markov model, drug discontinuation was not considered, and the respective definition used for drug wastage was the same. Since a dose reduction for ribociclib only results in unused tablets that can be administered in a subsequent cycle (Table 2), there is no drug wastage cost for ribociclib. Depending on when a dose reduction occurs for palbociclib, there may be drug wastage. A mid-cycle dose reduction will result in drug wastage for palbociclib (Table 2), while an end-of-cycle dose reduction results in no drug wastage. The difference in annual palbociclib drug costs for a mid-cycle versus end-of-cycle dose reduction provides an estimate for the cost of drug wastage associated with palbociclib.

\section{Retrospective Claims Analysis (Approach 3)}

Li et al. (2017) conducted a retrospective claims database analysis in a large nationally representative U.S. administrative claims database to assess the real-world palbociclib dosing patterns among postmenopausal women with HR+/ HER2- mBC and to estimate the effect of palbociclib dose changes on $\mathrm{mBC}$ treatment costs. ${ }^{6}$ Data from the Symphony Health Solutions database was extracted for this study. The database contains adjudicated claims from 27,000 U.S. pharmacies participating in commercial health plans, Medicare Part D, and Medicaid, as well as medical and pharmacy claims paid in cash. The Symphony Health database is a useful real-world data source for determining treatment patterns and outcomes related to new treatments because it captures most recent pharmacy and medical claims, with a lag period of approximately 45 days. Postmenopausal women with HR+/HER2 - mBC who initiated palbociclib-based therapy (initiation date $=$ index date) between February 3, 2015 (palbociclib approved by the U.S. Food and Drug Administration [FDA]) and February 29, 2016, and continuous quarterly activity 1 year before and 6 months after the index date were identified in the database. Rates of dose reduction were assessed, and drug wastage cost was estimated based on overlapping days between 2 prescription fills: the last original dose fill and the first reduced dose fill.

\section{Results}

\section{Drug Wastage}

In the Markov and PAC models, dose reductions for ribociclib patients did not result in drug wastage, while dose reductions for palbociclib did result in wastage (Table 2). 


\section{TABLE 1 Pharmacy Acquisition Cost Model}

\begin{tabular}{|c|c|c|c|c|c|c|c|c|c|c|c|}
\hline $\begin{array}{l}\text { WAC Pricing } \\
\text { (June } 28,2017 \text { ) }\end{array}$ & & Dose Reductions & $\begin{array}{l}\text { Treated } \\
\text { Patients }\end{array}$ & $\begin{array}{c}\text { Patients } \\
\text { on Stable } \\
\text { Dose } \\
\%\end{array}$ & $\begin{array}{c}\text { Dose } \\
\text { Reductions } \\
\mathrm{n}\end{array}$ & \multirow{2}{*}{\multicolumn{3}{|c|}{$\begin{array}{c}\begin{array}{c}\text { Mid-Cycle Dose } \\
\text { Reduction }\end{array} \\
\begin{array}{c}\text { Month supply } \\
\text { at each dose }\end{array} \\
\end{array}$}} & \multirow{2}{*}{\multicolumn{3}{|c|}{$\begin{array}{c}\text { End-of-Cycle Dose } \\
\text { Reduction }\end{array}$}} \\
\hline & \multirow[t]{2}{*}{$\begin{array}{l}\text { Month } \\
\text { supply }\end{array}$} & & & & & & & & & & \\
\hline Palbociclib & & $\begin{array}{c}\text { Palbociclib } \\
\text { (Symphony } \\
\text { claims) }\end{array}$ & & & & $125 \mathrm{mg}$ & $100 \mathrm{mg}$ & $75 \mathrm{mg}$ & $125 \mathrm{mg}$ & $100 \mathrm{mg}$ & $75 \mathrm{mg}$ \\
\hline $125 \mathrm{mg}$ & $\$ 11,291.94$ & $125 \mathrm{mg}$ & 74 & $74 \%$ & 0 & 12 & & & 12 & & \\
\hline $100 \mathrm{mg}$ & $\$ 11,291.94$ & $100 \mathrm{mg}$ & 19 & $19 \%$ & 1 & 3 & 10 & & 3 & 9 & \\
\hline \multirow[t]{2}{*}{$75 \mathrm{mg}$} & $\$ 11,291.94$ & $75 \mathrm{mg}$ & 7 & $7 \%$ & 2 & 3 & 2 & 9 & 3 & 1 & 8 \\
\hline & & & & $100 \%$ & & \multicolumn{3}{|c|}{$\begin{array}{l}\text { Assumption: If first dose } \\
\text { reduction is mid-cycle, the } \\
\text { second dose reduction is also } \\
\text { mid-cycle }\end{array}$} & \multicolumn{3}{|c|}{$\begin{array}{l}\text { Assumption: If first dose } \\
\text { reduction is at cycle end, the } \\
\text { second dose reduction is also } \\
\text { at cycle end }\end{array}$} \\
\hline Ribociclib & & $\begin{array}{c}\text { Ribociclib } \\
\text { (MONALEESA-2) }^{\mathbf{b}}\end{array}$ & & & & $600 \mathrm{mg}$ & $400 \mathrm{mg}$ & $200 \mathrm{mg}$ & $600 \mathrm{mg}$ & $400 \mathrm{mg}$ & $200 \mathrm{mg}$ \\
\hline $600 \mathrm{mg}$ & $\$ 11,955.21$ & $600 \mathrm{mg}$ & 51 & $51 \%$ & 0 & 12 & 12 & & & & \\
\hline $400 \mathrm{mg}$ & $\$ 9,564.17$ & $400 \mathrm{mg}$ & 30 & $30 \%$ & 1 & 3 & 10 & 3 & 9 & & \\
\hline \multirow{2}{*}{$200 \mathrm{mg}$} & $\$ 4,782.08$ & $200 \mathrm{mg}$ & 19 & $19 \%$ & 2 & 3 & 2 & 9 & 3 & 1 & 8 \\
\hline & & & & $100 \%$ & & & & & & & \\
\hline Total patients treated, $\mathbf{n}$ & & & 100 & & & & & & & & \\
\hline $\begin{array}{l}\text { Timing of dose reductions } \\
\text { (PALOMA-2 and } \\
\text { MONALEESA-222,24) }\end{array}$ & \multicolumn{5}{|l|}{ Months } & & & & & & \\
\hline First dose reduction & 3 & \multicolumn{4}{|c|}{$\begin{array}{l}\text { Taken from median TTD in PALOMA-2 as well as } \\
\text { MONALEESA-2 studies }\end{array}$} & & & & & & \\
\hline Second dose reduction & 4 & \multicolumn{4}{|l|}{ Assumption } & & & & & & \\
\hline Treatment duration & 12 & & & & & & & & & & \\
\hline
\end{tabular}

Note: Cells in orange can be modified by the user.

aFrom Symphony Health Solutions database.

${ }^{b}$ Base case is MONALEESA-2; user can also select MONALEESA-3 (62\%, 30\%, and 8\%) or MONALEESA-7 (65\%, 27\%, and 8\%).

TTD = timing of dose reductions; WAC $=$ wholesale acquisition cost.

For palbociclib, monthly dosing is once daily (3 weeks on therapy and 1 week off therapy for a total of 21 capsules monthly). ${ }^{7}$ Since palbociclib is supplied as 21 capsules at dosage strengths of $125 \mathrm{mg}, 100 \mathrm{mg}$, and $75 \mathrm{mg}$, a dose reduction at day 14 results in 7 capsules of the higher dose wasted for each dose reduction (Table 2).

\section{Markov Model}

Since transition probabilities were assumed to be the same for both treatments, the distribution of patients on doses and discontinuations were the same. Therefore, among the 100 ribociclib users, at 52 weeks, 38 patients had discontinued ribociclib therapy, and of the remaining 62 patients, 43 were on $600 \mathrm{mg}$ dosage, $16 \mathrm{on} 400 \mathrm{mg}$ dosage, and 3 on $200 \mathrm{mg}$ dosage. Likewise, among the 100 palbociclib users, at 52 weeks, 38 patients had discontinued palbociclib therapy, and of the remaining 62 patients, 43 were on $125 \mathrm{mg}$ dosage, 16 on $100 \mathrm{mg}$ dosage, and 3 on $75 \mathrm{mg}$ dosage. Nearly 30 palbociclib patients experienced dose reductions, resulting in 209 capsules being classified as drug wastage at a total cost of $\$ 112,382$, or approximately $\$ 1,124$ per patient per year. There was no drug wastage associated with ribociclib usage (Table 3).

\section{Pharmacy Acquisition Cost Model}

Based on the difference in annual costs of palbociclib treatment (mid-cycle vs. end-of-cycle), a mid-cycle dose reduction resulted in a drug wastage cost of $\$ 3,727$ per patient based on dose reduction data seen in actual clinical practice from the Symphony Health Solutions database (Table 4). The annual cost of treatment per patient for palbociclib was $\$ 139,230$ for dose reductions occurring mid-cycle, while the annual cost of treatment per patient for ribociclib was $\$ 131,244$ for a dose 


\section{TABLE 2 Ribociclib Tablets or Palbociclib Capsules Surplus or Wasted Due to Dose Reduction}

\begin{tabular}{|c|c|c|c|c|c|c|}
\hline & \multicolumn{3}{|c|}{ Ribociclib Dose Change } & \multicolumn{3}{|c|}{ Palbociclib Dose Change } \\
\hline & $\begin{array}{c}600 \mathrm{mg} \text { to } \\
400 \mathrm{mg}\end{array}$ & $\begin{array}{c}600 \mathrm{mg} \text { to } \\
200 \mathrm{mg}\end{array}$ & $\begin{array}{l}400 \mathrm{mg} \text { to } \\
200 \mathrm{mg}\end{array}$ & $\begin{array}{c}125 \mathrm{mg} \text { to } \\
100 \mathrm{mg}\end{array}$ & $\begin{array}{l}125 \mathrm{mg} \text { to } \\
75 \mathrm{mg}\end{array}$ & $\begin{array}{c}100 \mathrm{mg} \text { to } \\
75 \mathrm{mg}\end{array}$ \\
\hline Initial daily dose at start of cycle & $600 \mathrm{mg}$ & $600 \mathrm{mg}$ & $400 \mathrm{mg}$ & $125 \mathrm{mg}$ & $125 \mathrm{mg}$ & $100 \mathrm{mg}$ \\
\hline Daily dose after change & $400 \mathrm{mg}$ & $200 \mathrm{mg}$ & $200 \mathrm{mg}$ & $100 \mathrm{mg}$ & $75 \mathrm{mg}$ & $75 \mathrm{mg}$ \\
\hline Day in cycle dose reduction & Day 14 & Day 14 & Day 14 & Day 14 & Day 14 & Day 14 \\
\hline Number of tablets/capsules dispensed & 63 & 63 & 42 & 21 & 21 & 21 \\
\hline Number of tablets/capsules used before dose change at day 14 & 42 & 42 & 28 & 14 & 14 & 14 \\
\hline Number of tablets/capsules needed for remainder of cycle & 14 & 7 & 7 & 7 & 7 & 7 \\
\hline Number of $200 \mathrm{mg}$ tablets surplus by adjusting for dose change & 7 & 14 & 7 & & & \\
\hline Number of capsules wasted by adjusting for dose change & & & & 7 & 7 & 7 \\
\hline
\end{tabular}

reduction occurring mid-cycle, a difference in annual treatment costs of $\$ 7,985$ per patient per year (Table 4). Consistent with no unused drug supplied for end-of-cycle dose reductions, annual costs of treatment for palbociclib $(\$ 135,503)$ and ribociclib $(\$ 125,649)$ were lower than their treatment costs with mid-cycle dose reduction.

\section{Retrospective Claims Analysis}

There were 1,242 patients that initiated palbociclib therapy (mean age 62.7 years, with median follow-up of 8.7 months). During the 12-month post-index period, across the first 4 lines, dose reduction rates were between $31.9 \%$ and $33.7 \%$. A total of 411 (33.1\%) patients changed dose, among whom 128 (31.1\%) experienced prescription fill overlap (average $=11.1$ days). Mean potential drug wastage cost among patients with fill overlap was $\$ 5,471$.

\section{Discussion}

As new alternative payment models focus on total cost of care, such as the Oncology Care Model, ${ }^{12}$ opportunities for cost savings, such as wastage, are gaining increased attention. Recently, the Academy of Managed Care Pharmacy has identified minimizing drug wastage as a key area of interest for improving efficiency and cutting costs within the pharmacy benefit, ${ }^{3}$ and the Centers for Medicare $\&$ Medicaid Services now require Medicare Part D sponsors to implement programs designed to minimize drug waste. ${ }^{13}$

Because of the significant pharmacy costs incurred by oncology drugs and the potential for high drug wastage associated with dose adjustments and early discontinuation, drug wastage is an important component in the economic evaluations of drugs. However, few economic studies to date have included drug wastage in their analyses; in fact, many assume zero drug wastage, providing an incomplete picture of a drug's actual cost, cost-effectiveness, and value..$^{14-16}$

Early discontinuation of oral chemotherapy agents due to toxicities and other adverse events is a common problem. ${ }^{17} \mathrm{~A}$
2009 study showed that the discontinuation rate for medicationnaive patients taking chemotherapy agents for breast cancer was $41.8 \%$ within the first 30 days. Even for medication-experienced patients, the discontinuation rate in the first 30 days was $11.3 \% .{ }^{18}$

Dose reduction rates for breast cancer drugs can also be high. A 2016 retrospective cohort study showed 31\% of patients with $\geq 6$ months follow-up had experienced dose reductions, and $15 \%$ had discontinued palbociclib. ${ }^{19}$ In a separate claims database analysis by Baird et al. (2015), 17.8\% of palbociclib patients had a dose reduction, with $90 \%$ of dose reductions occurring during the first or second treatment cycle. ${ }^{20}$ In the 3 trials, the rate of dose reductions was $40 \%$ in PALOMA-1, $36 \%$ in PALOMA-2, and 34\% in PALOMA-3. ${ }^{21-23}$ The proportions of patients experiencing 1 or 2 dose reductions, however, was not reported in any of the PALOMA trials.

The Markov model used MONALEESA-2 dose reduction proportions for ribociclib and palbociclib, with $30 \%$ of patients experiencing 1 dose reduction and 19\% of patients experiencing 2 dose reductions, for a total of $49 \%$ of patients experiencing dose reductions. The PAC model used the MONALEESA-2 dose reduction proportions for ribociclib (base case) and the Symphony Health Solutions database dose reduction proportions for palbociclib (19\% with 1 dose reduction and $7 \%$ with 2 dose reductions; overall $26 \%$ of patients with dose reductions). It should be noted that the PAC model does allow the user to also select the dose reduction proportions for ribociclib from MONALEESA-3 or -7 as well $(62 \%, 30 \%, 8 \%$ or $65 \%, 27 \%, 8 \%$, respectively). In MONALEESA-7, 35\% of patients experienced dose reductions, which resulted in slightly higher annual treatment costs for ribociclib at mid-cycle $(\$ 136,600)$ and a smaller difference in annual treatment cost mid-cycle between palbociclib and ribociclib $(\$ 2,630)$. Since dose reductions for ribociclib do not result in drug wastage, it may be a moot point as to the dose reduction proportions used for ribociclib. Palbociclib drug wastage, however, is affected by the dose reduction proportions used, with lower dose reduction proportions decreasing drug wastage costs and higher dose reduction proportions being associated with increasing drug wastage costs. 
With palbociclib, adverse events-identified by monitoring at week 2 of a monthly cycle-may result in a $25 \mathrm{mg}$ dose reduction ( $125 \mathrm{mg}$ to $100 \mathrm{mg}$ or $100 \mathrm{mg}$ to $75 \mathrm{mg}$ ) with a maximum of 2 dose reductions allowed. In the claims database analysis by Baird et al., the authors estimated that drug wastage occurred in one third of patients who reduced their doses of palbociclib. ${ }^{20}$ Recently, drug wastage associated with palbociclib was reported using real-world data from the Symphony Health Solutions database. ${ }^{6,9}$ The authors estimated the costs of potential palbociclib wastage related to dose modifications by applying WAC (as of October 2016) to the number of overlapping days of supply between 2 adjacent fills. Dose reductions occurred in $33.1 \%$ of patients, with an average overlap in palbociclib prescription fills with different doses of 11.1 days.

The dose reduction rate in the real-world study was similar to that used in both models, and the overlap of 11.1 days was greater than the overlap used in the models (dose reduction on day 14 would only result in 7 days of overlap). It is important to note that the median length of follow-up in the claims analysis was 8.7 months and that the Markov and PAC models estimated drug wastage over 12 months.

Our calculations from the Markov model and the PAC model estimate that drug wastage costs for palbociclib is $\$ 1,124$ and $\$ 3,727$ per patient per year, respectively, and that ribociclib is not associated with drug wastage costs due to the flexible dosing that allows unused $200 \mathrm{mg}$ tablets to be administered in future cycles. Since ribociclib is supplied in a blister package for each of the 3 doses, it is possible that some patients may receive a new prescription when a dose reduction occurs. The present analysis assumed that unused tables can be used in future cycles. If this did not happen, drug wastage costs for palbociclib and ribociclib would be very similar.

It is important to point out that drug wastage is dependent on when in the treatment cycle a dose reduction occurs. Since FDA labeling for palbociclib states that monitoring should occur on day 15 of the treatment cycle, ${ }^{7}$ day 14 was chosen as the day in the cycle when a dose reduction would occur. In actual clinical practice, a dose reduction could occur at other times in the treatment cycle, resulting in wastage different than predicted by either model. If the dose reduction occurred earlier in the cycle, more drug would be wasted, which would result in higher drug wastage costs; if it occurred later, less drug would be wasted. Dose reductions that occur at the end of a treatment cycle would result in no drug wastage.

The PAC model was developed to estimate total annual drug acquisition costs, including the costs of drug treatment and drug wastage. The annual drug costs for a patient treated with either ribociclib or palbociclib was $\$ 131,244$ or $\$ 139,230$, respectively (Table 4). Annual treatment costs with ribociclib were $\$ 7,985$ lower than palbociclib and were not associated with any drug wastage costs. In addition, with ribociclib's single dosage form of $200 \mathrm{mg}$, tablets can be combined to meet

\section{TABLE 3 Markov Model Results for Ribociclib} and Palbociclib

\begin{tabular}{l|c}
\hline Ribociclib & $\mathrm{N}$ or $\$$ \\
\hline All patients & 100 \\
\hline $200 \mathrm{mg}$ tablets wasted for $600 \mathrm{mg}$ dose & 0 \\
\hline $200 \mathrm{mg}$ tablets wasted for $400 \mathrm{mg}$ dose & 0 \\
\hline $200 \mathrm{mg}$ tablets wasted for $200 \mathrm{mg}$ dose & $\$ 0$ \\
\hline Costs for wastage of $600 \mathrm{mg}$ dose & $\$ 0$ \\
\hline Costs for wastage of $400 \mathrm{mg}$ dose & $\$ 0$ \\
\hline Costs for wastage of $200 \mathrm{mg}$ dose & $\$ 0$ \\
\hline Costs of discontinuation $(600 \mathrm{mg}$ dose $)$ & $\$ 0$ \\
\hline Costs of discontinuation $(400 \mathrm{mg}$ dose $)$ & $\$ 0$ \\
\hline Costs of discontinuation $(200 \mathrm{mg}$ dose $)$ & $\$ 0$ \\
\hline Total cost & $\$ 0$ \\
\hline Total cost per patient & $\mathrm{N}$ or $\$$ \\
\hline Palbociclib & 100 \\
\hline All patients & 184 \\
\hline $125 \mathrm{mg}$ capsule wasted & 25 \\
\hline 100 mg capsule wasted & 0 \\
\hline $75 \mathrm{mg}$ capsule wasted & $\$ 98,939$ \\
\hline Costs for wastage of $125 \mathrm{mg}$ dose & $\$ 13,443$ \\
\hline Costs for wastage of $100 \mathrm{mg}$ dose & $\$ 0$ \\
\hline Costs for wastage of $75 \mathrm{mg}$ dose & $\$ 0$ \\
\hline Costs of discontinuation $(125 \mathrm{mg}$ dose $)$ & $\$ 0$ \\
\hline Costs of discontinuation $(100 \mathrm{mg}$ dose $)$ & $\$ 0$ \\
\hline Costs of discontinuation $(75 \mathrm{mg}$ dose $)$ & $\$ 1,124$ \\
\hline Total costs & \\
\hline Total cost per patient & 382 \\
\hline
\end{tabular}

prescribed dosages. By providing more flexibility in dosages, ribociclib may reduce the related drug wastage to nearly zero, representing significant potential cost savings to payers.

\section{Limitations}

This study has limitations to consider. The definition of drug wastage used in both models was defined as a drug dosage that could not be used in subsequent cycles. Discontinuation was not considered in the definition of drug wastage for 2 reasons. First, discontinuation rates are similar for both drugs as reported in the FDA labeling (ribociclib, 7\% due to adverse reactions $^{8}$; palbociclib, 9.7\% [Study 1] and 6\% [Study 2]). Second, in case of drug discontinuation, tablets and capsules remaining are usually disposed of, so the effect on payers is the same for both drugs.

If dose reduction occurs within the first couple of months of the year, the potential savings with ribociclib versus palbociclib would be greatest, while a dose reduction occurring at later months in the first year would minimize the potential savings. The Markov and PAC models only estimated cost savings for the first year of treatment and did not consider the savings that could result from treatment beyond 1 year. While these savings could extend for the duration of treatment, often greater than 


\begin{tabular}{|c|c|c|}
\hline $\begin{array}{c}\text { TABLE 4 Pharm } \\
\text { Annua }\end{array}$ & \multicolumn{2}{|c|}{$\begin{array}{l}\text { Pharmacy Acquisitions Cost Model: Total } \\
\text { Annual Treatment Costs }\end{array}$} \\
\hline & $\begin{array}{l}\text { Mid-Cycle Dose } \\
\text { Reduction }\end{array}$ & $\begin{array}{l}\text { End-of-Cycle Dose } \\
\text { Reduction }\end{array}$ \\
\hline \multicolumn{3}{|c|}{ Annual drug costs of treatment per patient } \\
\hline \multicolumn{3}{|l|}{ Palbociclib } \\
\hline $125 \mathrm{mg}$ & 100,272 & 100,272 \\
\hline $100 \mathrm{mg}$ & 27,891 & 25,746 \\
\hline $75 \mathrm{mg}$ & 11,066 & 9,485 \\
\hline Total annual costs & 139,230 & 135,503 \\
\hline \multicolumn{3}{|l|}{ Ribociclib } \\
\hline $600 \mathrm{mg}$ & 73,166 & 73,166 \\
\hline $400 \mathrm{mg}$ & 39,452 & 36,583 \\
\hline $200 \mathrm{mg}$ & 18,626 & 15,900 \\
\hline Total annual costs & 131,244 & 125,649 \\
\hline \multicolumn{3}{|c|}{ Annual drug costs of treatment for population of treated patients } \\
\hline \multicolumn{3}{|l|}{ Palbociclib } \\
\hline $125 \mathrm{mg}$ & $10,027,243$ & $10,027,243$ \\
\hline $100 \mathrm{mg}$ & $2,789,109$ & $2,574,562$ \\
\hline $75 \mathrm{mg}$ & $1,106,610$ & 948,523 \\
\hline Total annual costs & $13,922,962$ & $13,550,328$ \\
\hline \multicolumn{3}{|l|}{ Ribociclib } \\
\hline $600 \mathrm{mg}$ & $7,316,589$ & $7,316,589$ \\
\hline $400 \mathrm{mg}$ & $3,945,220$ & $3,658,295$ \\
\hline $200 \mathrm{mg}$ & $1,862,621$ & $1,590,042$ \\
\hline Total annual costs & $13,124,430$ & $12,564,926$ \\
\hline $\begin{array}{l}\text { Net annual cost savings for } \\
100 \text { patients }\end{array}$ & 798,532 & 985,402 \\
\hline $\begin{array}{l}\text { Net cost savings per patient } \\
\text { per year }\end{array}$ & 7,985 & 9,854 \\
\hline
\end{tabular}

24 months, ${ }^{22}$ a 1-year time frame was used, since this may be most relevant for payers.

The Markov model used individual patient-level data from the MONALEESA-2 (ribociclib) clinical trial to determine the transition probabilities for dose reduction and treatment discontinuation. These same transition probabilities were used for palbociclib as well, since the authors did not have access to similar patient-level data from the trials for palbociclib. Since the proportions of patients with dose reductions was similar (palbociclib, 36\% vs. ribociclib, 45\%) as reported in the FDA labeling, 7,8 the effect of this limitation may be minimal.

The 2 models assumed that surplus ribociclib tablets can be used in subsequent treatment cycles when a dose reduction occurs. If this is not the case, then there will be drug wastage costs for ribociclib dose reductions as well, and overall drug wastage costs for palbociclib and ribociclib would be similar. A real-world study of ribociclib dosing patterns is needed to determine if this assumption is valid.

\section{Conclusions}

Metastatic breast cancer patients receiving treatment commonly experience adverse events that may lead to dose reductions and increased drug treatment costs. This study summarized 3 methods for estimating the total costs of drug treatment, including the costs of drug wastage resulting from dose reduction. A Markov model using clinical trial data predicted patient transitions to various doses and treatment discontinuation. A PAC model quantified the difference in annual drug acquisition costs and incorporated clinical trial and realworld dose reduction data. An observational real-world pharmacy claims analysis used quantity supplied and overlapping days of different dosages to estimate dose reductions. These 3 methods provide payers with different approaches to estimate the cost of drug wastage and its effect on total treatment costs.

\section{Authors}

JOSEPH BISKUPIAK, PhD, MBA; GARY ODERDA, PharmD, MPH; and DIANA BRIXNER, PhD, RPh, University of Utah College of Pharmacy, Salt Lake City. DEREK TANG, PhD, BSPharm; CHRISTOPHER ZACKER, RPh, PhD; and ANAND A. DALAL, $\mathrm{PhD}, \mathrm{MBA}$, Novartis Pharmaceuticals, East Hanover, New Jersey.

AUTHOR CORRESPONDENCE: Joseph Biskupiak, PhD, MBA, University of Utah College of Pharmacy, 30 South 2000 East, Salt Lake City, UT 84112. Tel.: 801.585.5249;

E-mail: Joseph.Biskupiak@pharm.utah.edu.

\section{DISCLOSURES}

This study received financial support from Novartis Pharmaceuticals, which has products approved for treatment of breast cancer. Tang was employed by Novartis during this study; Zacker and Dalal are employed by Novartis and own company stock. Biskupiak, Brixner, and Oderda received payment from Novartis for this study. Brixner serves as a consultant for Millcreek Outcomes Group and also declares consulting fees from Abbvie, AstraZeneca, Abbott, Becton Dickinson, and Xcenda, unrelated to this study.

\section{ACKNOWLEDGMENTS}

The authors acknowledge medical writer Kelley J. P. Lindberg for her assistance in editing this manuscript.

\section{REFERENCES}

1. Fasola G, Aita M, Marini L, et al. Drug waste minimisation and cost-containment in medical oncology: two-year results of a feasibility study. BMC Health Serv Res. 2008;8:70.

2. Law AV, Sakharkar P, Zargarzadeh A, et al. Taking stock of medication wastage: unused medications in U.S. households. Res Social Adm Pharm. 2015;11(4):571-78.

3. Academy of Managed Care Pharmacy. Fraud, waste, and abuse in prescription drug benefits. 2015. Available at: http://www.amcp.org/WorkArea/ DownloadAsset.aspx?id=19633. Accessed June 13, 2019.

4. Howard DH, Bach PB, Berndt ER, Conti RM. Pricing in the market for anticancer drugs. J Econ Perspect. 2015;29(1):139-62.

5. Bach PB, Conti RM, Muller RJ, Schnorr GC, Saltz LB. Overspending driven by oversized single dose vials of cancer drugs. BMJ. 2016;352:1788 
6. Li N, Du EX, Chu L, et al. Real-world palbociclib dosing patterns and implications for drug costs in the treatment of HR+/HER2- metastatic breast cancer. Expert Opin Pharmacother. 2017;18(12):1167-78.

7. IBRANCE (palbociclib) capsules, for oral use. Pfizer. 2015.

8. KISQALI (ribociclib) tablets, for oral use. Novartis Pharmaceuticals. March 2017. Available at: https://www.accessdata.fda.gov/drugsatfda_docs/ label/2017/209092s000lbl.pdf. Accessed June 13, 2019.

9. Li N, Du EX, Chu L, Peeples M, Xie J, Barghout V. Real-world palbociclib dosing patterns and potential wastage associated with dose modificationss among post-menopausal women with HR-positive/HER2-negative metastatic breast cancer (mBC) [abstract]. J Clin Oncol. 2017;35(8 Suppl):17. Available at: https://ascopubs.org/doi/abs/10.1200/JCO.2017.35.8_suppl.17. Accessed June 13, 2019.

10. Truven Health Analytics/IBM Watson Health. IBM micromedex RED BOOK Online. Available at: https://www.ibm.com/us-en/marketplace/ micromedex-red-book. Accessed June 25, 2019.

11. Hortobagyi GN, Stemmer SM, Burris HA, et al. Ribociclib as firstline therapy for HR-positive, advanced breast cancer. New Eng J Med. 2016;375(18):1738-48.

12. Kline R, Adelson K, Kirshner JJ, et al. The Oncology Care Model: perspectives from the Centers for Medicare \& Medicaid Services and participating oncology practices in academia and the community. Am Soc Clin Oncol Educ Book. 2017;37:460-66

13. Centers for Medicare \& Medicaid Services. Prescription drug benefit manual. Chapter 9-compliance program guidelines. Revised September 11, 2013. Available at: https://www.cms.gov/Medicare/Prescription-DrugCoverage/PrescriptionDrugCovContra/Downloads/Chapter9.pdf. Accessed June 15, 2019.

14. Lien K, Cheung MC, Chan KK. Adjusting for drug wastage in economic evaluations of new therapies for hematologic malignancies: a systematic review. J Oncol Pract. 2016;12(4):e369-79.

15. Valgus JM. Cancer drug wastage: the hidden cost in value-based cancer care delivery. Cancer. 2017;123(18):3445-46.

16. Truong J, Cheung MC, Mai H, et al. The impact of cancer drug wastage on economic evaluations. Cancer. 2017;123(18):3583-90.
17. Khandelwal N, Duncan I, Ahmed T, Rubinstein E, Pegus C. Impact of clinical oral chemotherapy program on wastage and hospitalizations. Am J Manag Care. 2011;17(5 Spec No):e169-73.

18. Vanelli M, Pedan A, Liu N, Hoar J, Messier D, Kiarsis K. The role of patient inexperience in medication discontinuation: a retrospective analysis of medication nonpersistence in seven chronic illnesses. Clin Ther. 2009;31(11):2628-52

19. Patt D, Mitra D, Harrell R, et al. Early treatment utilization of palbociclib for metastatic breast cancer (mBC) in a U.S. community oncology network. [abstract] J Clin Oncol. 2016;34(15 Suppl):e18112. Available at: https://ascopubs.org/doi/abs/10.1200/JCO.2016.34.15_suppl.e18112. Accessed June 18, 2019

20. Baird J, Starner C, Bowen K, Gleason P. Palbociclib (Ibrance) utilization and costs among 18 million insured Americans: managed care pharmacy opportunities [abstract]. J Manag Care Spec Pharm. 2015;21(10a Suppl):S21. Available at: https://www.jmcp.org/doi/pdf/10.18553/jmcp.2015.21.10.S1.

21. Finn RS, Crown JP, Lang I, et al. The cyclin-dependent kinase $4 / 6$ inhibitor palbociclib in combination with letrozole versus letrozole alone as first-line treatment of oestrogen receptor-positive, HER2-negative, advanced breast cancer (PALOMA-1/TRIO-18): a randomised phase 2 study. Lancet Oncol. 2015;16(1):25-35.

22. Finn RS, Martin M, Rugo HS, et al. Palbociclib and letrozole in advanced breast cancer. New Engl J Med. 2016;375(20):1925-36.

23. Cristofanilli M, Turner NC, Bondarenko I, et al. Fulvestrant plus palbociclib versus fulvestrant plus placebo for treatment of hormonereceptor-positive, HER2-negative metastatic breast cancer that progressed on previous endocrine therapy (PALOMA-3): final analysis of the multicentre, double-blind, phase 3 randomised controlled trial. Lancet Oncol. 2016;17(4):425-39.

24. Janni W, Burris HA, Blackwell KL, et al. First-line ribociclib plus letrozole for postmenopausal women with hormone receptor-positive (HR+), HER2-negative (HER2-) advanced breast cancer (ABC): MONALEESA-2 safety results [abstract]. J Clin Oncol. 2017;35(15 Suppl):1047. Available at: https://ascopubs.org/doi/abs/10.1200/JCO.2017.35.15_suppl.1047. Accessed June 18, 2019 